\title{
Analysis of Principle and Key Technology of the Hybrid Power Generation System with Wind Turbine, Photovoltaic and Electric Storage
}

\author{
Hongchun Yao and Ming Xu
}

\begin{abstract}
This paper proposes the meaning and essentiality of developing the hybrid power generation system with wind turbine, photovoltaic and electric storage, and expatiates the basic principle of the system. Then, this paper discusses the key technology of Wind-PV-ES ratio optimization algorithm, hybrid power generation system optimization integration, power estimation, integrated monitoring, and maintenance. Finally, the development and application outlook of the system in China is analyses and proved.
\end{abstract}

Index Terms-Wind-PV-ES, hybrid power generation, system optimization integration, integrated monitoring.

\section{INTRODUCTION}

The large-scale development and utilization of renewable energy, such as solar and wind, provides fresh vitality for the future development of the global energy industry with its unique resources and environmental advantages. According to the forecast of the European JRC, renewable energy will account for more than $30 \%$ of the total energy consumption by 2030 , and this number will become more than $50 \%$ by 2040. Therefore, development of renewable energy has become the important strategy to ensure energy security, optimize energy structure, protect the ecological environment, and reduce greenhouse gas emissions. In November 2009, the Chinese government announced action to control greenhouse gas emissions, and the target is to ensure Carbon dioxide emissions per unit of GDP in China in 2020 than in 2005 decreased by $40-45 \%$.

Although large-scale development of new energy is the trend, the large-scale development of intermittent energy such as wind power and photovoltaic faces three major technical problems. The first is the power generation characteristics need to be improved because of the randomness volatility and intermittence. The second is that the power is difficult to forecasting, scheduling and control. The third is resources and demands are geographically reverse distribution, and the efficient allocation of resources issues needs to be resolved. The three major problems become the bottleneck restricting the development of China's new energy, and affect the goal of China's new energy development[1].

For the above-mentioned technical problems, we can

Manuscript received October 18, 2012; revised November 21, 2012.

Hongchun Yao is with the China Electric Power Research Institute, Nanjing, 210003, China (e-mail: yaohongchun@yahoo.com.cn).

Ming Xu is with the Jibei Electric Power Company, Beijing, 100053, China (e-mail: yhc82yhc@yahoo.com.cn). consider the solutions from the grid and power sources on both sides: on the one hand, we start from the grid side to improve the power grid planning, design, control and scheduling level, so that the electricity can be timely sent; on the other hand, we start from the power supply side, implement the energy storage technology to stabilize fluctuations of electricity, and send in accordance with the actual needs. The hybrid power generation system with wind turbine, photovoltaic and electric storage is the organic combination of the above two workarounds, and the system can promote the grid transmission capacity and the power scheduling capability by making use of grid planning and improving the output characteristics of the new energy.

\section{BASIC PRINCIPLE}

\section{A. Analysis of the Characteristics of Wind and Photovoltaic Power Resources}

In some areas, there is a natural complementarity between wind power and photovoltaic power generation characteristics. According to the statistics of day, generally speaking, the electric generation of wind turbine in the daytime is smaller than in the evening, and according to the statistics of year, wind power is strong and solar radiation is weak in winter, but the situation is opposite in summer. The preliminary research results show that, if we build the co-generation system with wind and photovoltaic power by a certain proportion of reasonable configuration, the output power of the system is strong during the day and weak at night, and the characteristic may be close to the actual transmission needs of the grid. Of course, such a co-generation system can not eliminate volatility, intermittence and randomness, but can ease this feature, so we can convert two complex problem to a relatively easy problem by reasonable configuration.

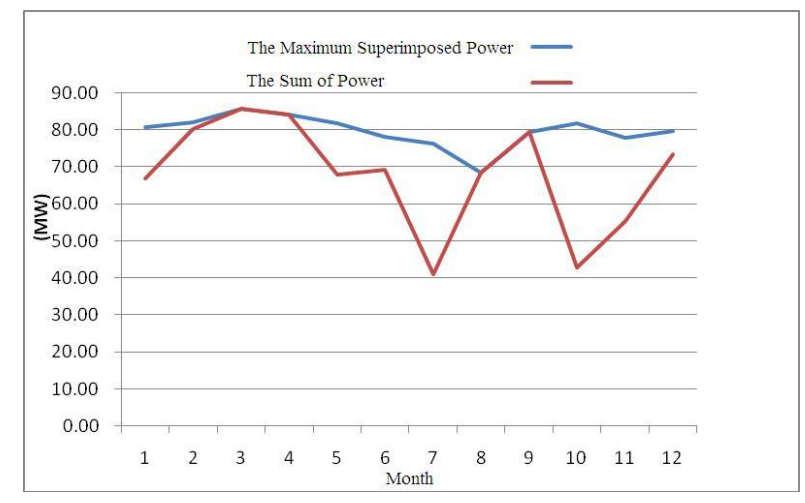

Fig. 1. The maximum curve of superposition of wind and solar power (1:1) 
We analysis the wind and photovoltaic resource characteristic of someplace in north China, the maximum curves of superimposed power are shown in Fig. 1 and Fig. 2.

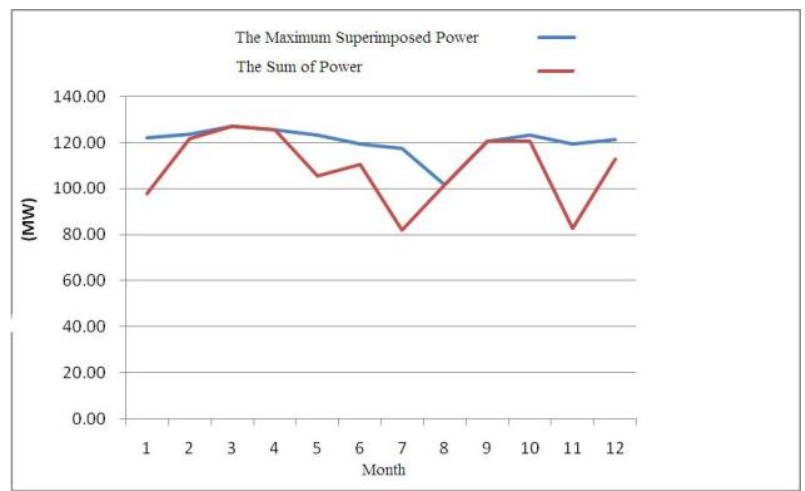

Fig. 2. The maximum curve of superposition of wind and solar power $(2: 1)$

From the figures we can see, in most of the months, the maximum superimposed power of wind and photovoltaic is significantly lower than the sum of the maximum power of wind and photovoltaic. This phenomenon indicates that wind and photovoltaic resources are inconsistent in time, and the peak area is not in the same time. Usually, when the wind is weak, the photovoltaic is strong, and the converse situation is true, so it reflects the complementarity of wind and photovoltaic.

\section{B. Analysis of Energy Storage}

According to the actual situation of wind- photovoltaic resources and load, the reasonable proportion of wind power and photovoltaic power generation can be configurated to take advantage of the nature complementary characteristic of wind- photovoltaic resources, which eases the volatility, intermittency and randomness of the co-generation system, but can not completely solve these problems. As clean energy in power systems, wind power and photovoltaic power should be accepted and the load should be meeting as far as possible. In this way, the new energy and the load becomes rigid part of the grid on both sides, and then energy storage should play a role as a flexible link between them, and meet the demand of new energy acceptence and load consumption under the premise of safety and stability of power grids [2].

In the hybrid power generation system with wind turbine, photovoltaic and electric storage, the effect of energy storage system is related with its capacity and power, and if we configure more capacity and power, the effect is more significant. Generally speaking, in accordance with the capacity configuration of energy storage system from small to large, energy storage system can play four roles as fluctuation smoothing, planning tracking, load shifting and grid frequency adjusting [3].

The Fluctuation smoothing refers that we can make the joint power of wind turbine, photovoltaic and energy storage smoothly, so that the fluctuation of power in a certain time can be limit in a fixed range, then the requirement of energy storage is minimum, and can be implemented easily. [4] The planning tracking refers that the joint power can respond to the grid scheduling plan which is established by a dynamic process, on the one hand, the scheduling plan should be made reasonably by concerning the wind-photovoltaic resources, one the other hand, the energy storage capacity and the control technology is also put forward higher requirements[5]. The load shifting refers that the grid dispatching center could treat the hybrid power generation system as the conventional power plant, and dispatch instructions according to the grid condition, then he highest energy storage capacity and control technology is required. The grid frequency adjusting refers that the system makes fully use of the characteristics of control flexibility and fast respondence of energy storage system to participate in the grid frequency adjustment, then the energy storage system requires more power and less capacity, and could adopt a power-type or hybrid energy storage technology[6]-[ 9].

\section{KEY TECHNOLOGIES}

The key technologies of the hybrid power generation system include systems integration, power forecasting and comprehensive monitoring, and the main content of the key technologies described below.

\section{A. Systems Integration}

The system integration technologies include the optimization of system capacity ratio and the optimization of system collocation.

The optimization of system capacity ratio is made to achieve the goal of smoothing output power and improving energy efficiency. The technical method is to match the wind and photovoltaic power and extend the energy storage runtime by analysis of typical wind, photovoltaic and energy storage power characteristics. The capacity and power configuration of energy storage is related to the fluctuation level and control purpose. There is a certain difference between the power and capacity of the energy storage to improve wind-photovoltaic output power, so the configuration should be subject to different control purpose [10].

The optimization of system collocation is the research of wind-photovoltaic joint micro-siting technology based on the comprehensive consideration of the interaction between the wind turbines and solar panels.

\section{B. Power Forecasting}

Grid dispatching center can not instruct and implement accurate power generation plan for wind and photovoltaic generation as other traditional power plant, so we need to research and develop new energy power generation forecasting technologies, which include numerical weather forecasting technology and joint power forecasting technology

The numerical weather forecasting technology, which based on the global numerical weather forecasting result, selects the scheme with optimal parameters to simulate the mesoscale numerical weather forecasting, and get the result.

The joint power forecasting technology, which based on the wind-photovoltaic monitor network and numerical weather forecasting result, makes use of methods of theoretical analysis, computer simulation and statistical analysis of the actual data to propose the power forecasting 
model for a specific area, and does error analysis.

\section{Comprehensive Monitoring}

The comprehensive monitoring technology optimizes the realtime control of all subsystem, minimizes the significant, high-frequency fluctuations of wind-photovoltaic power, and reduces unpredictability of the whole system power output by the local control strategy of energy storage system. Further more, the technology can improve the capacity confidence of wind and photovoltaic power to reduce the backup capacity of the grid, and enhance the grid to accept wind and photovoltaic power [11], [12].

The technology includes data acquisition, joint control and dispatching, wind power control, photovoltaic power control and energy storage control, as shown in Fig. 3.

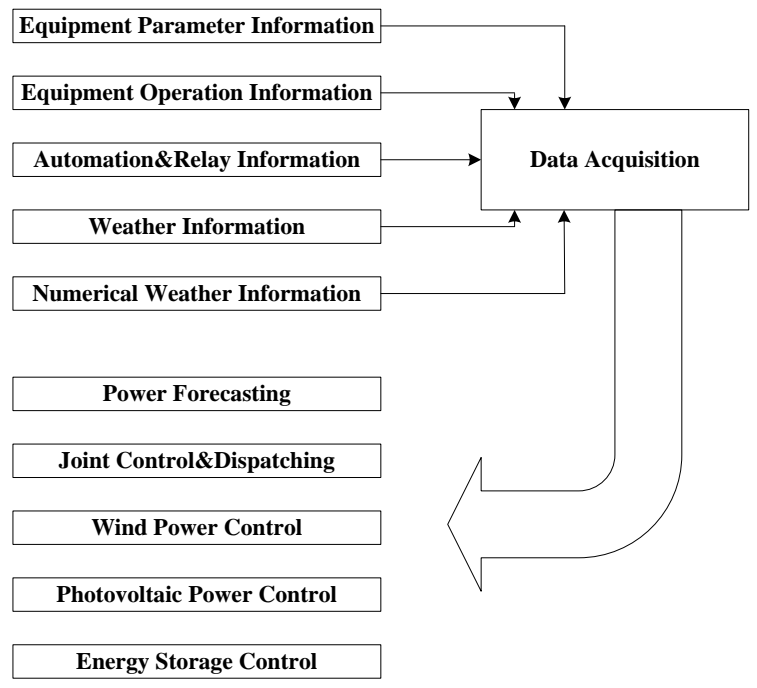

Fig. 3. Block diagram of integrated control

\section{CONCLUSION}

The hybrid power generation system with wind turbine, photovoltaic and electric storage can make new energy generation such as wind or photovoltaic power to achieve the characteristics of conventional power, so it is expected to crack the technical bottleneck of grid integration for massive new energy.

\section{REFERENCES}

[1] Y. Yu, H. D. Tang, and J. B. Guo, "Application Prospect of Wind-PV-ES Hybrid Power System," East China Electric Power, 2010, vol. 12, pp. 20-24.

[2] K. Wang, B. H. Zhang, and Y. Q. Hu, "Dynamic Economic Dispatch of Grid-Connected Wind Farm with Energy Storage Device," Journal of Hubei University of Technology, 2011, vol. 2, pp.1- 4.

[3] Y. H. Yang, J. Cheng, and G. P. Cao, "A gauge for direct economic benefits of energy storage devices," Battery Bimonthly, 2011, vol. 2, pp. 19-21.

[4] N. Sun, D. S. Xing, and H. L. Du, "Development and Applications of Wind-Solar Hybrid Power Generating System," Sanxi Electric Power, 2010, vol. 8, pp. 54-56.

[5] C. J. He, Y. Y. Wang , and S. N. Wu, "The Application of Wind and PV Hybrid Technology to Liaoling Power System," Northeast Electric Power Technology, 2009, vol. 12, pp. 27-31.

[6] H. B. Lu and Z. C. Fu, "Analysis of the feasibility of wind-light complementary system applied in the project," Shanxi Architecture, 2011, vol. 4, pp. 126-127.

[7] Z. K. Zhang, D. Y. Wang, Y. N. Chi, L. Y. Wang, and W. Sheng, "Study of transient stability enhancement of wind farm by application of superconducting magnetic energy storage devices," Power System Protection and Control, 2010, vol. 12, pp. 38-42.

[8] L. Ni, R. X. Yuan, Z. B. Zhang, and C. Liu, "Research on control method and dynamic characteristic of large wind farm integration," Power System Protection and Control, 2011, vol. 4, pp. 76-79.

[9] G. Y. Fan, K. P. Shi, L. M. Feng, S. R. Z. Y. Wang, LI, and J. Y. Fu, "Stability analysis and visualization study of wind power integration," Electric Power, 2011, vol. 4, pp. 11-14

[10] J. Zeng, "Simulation of Battery Energy Storage System Used for Wind Power Regulation," Southern Power System Technology, 2010, vol. 4, pp. 126-129.

[11] X. W. Zhang and J. J. Zheng, "Design of Monitoring System for Photovoltaic Power Station [M]," Electrotechnics and Electric, 2010, vol. 9, pp. 12-16.

[12] X. H. Wang, W. Q. Meng, and H. D. Liu, "The Research on Application and Development of Digital Wind Farm," North China Electric Power, 2011, vol. 3, pp. 33-36.

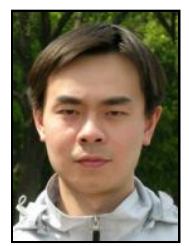

Hongchun Yao was born in China 1982, He received his bachelor degree from Nanjing Post \& Telecommunication University and master degree from State Grid Electric Power Research Institute. His major field of study is distributed generation, photovoltaic generation. Hongchun Yao is with the Renewable Energy Research Institute of China Electric Power Research Institute.

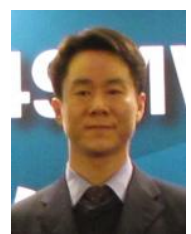

Ming Xu was born in China 1975, He received his bachelor degree from North China Electric Power University. His major field of study is wind power generation, photovoltaic generation and energy storage. Ming $\mathrm{Xu}$ is with the Jibei Electric Power Company. 